\title{
ANÁLISE DO CUSTO DE PRODUÇÃO E LUCRATIVIDADE DO MAMÃO FORMOSA, CULTIVADO NO MUNICÍPIO DE SANTA FÉ DO SUL (SP) ${ }^{1}$
}

\author{
MARILEY DE CASTRO ALMEIDA DA SILVA², MARIA APARECIDA ANSELMO TARSITANO, \\ LUIZ DE SOUZA CORREA ${ }^{3}$
}

\begin{abstract}
RESUMO - Este trabalho foi realizado no município de Santa Fé do Sul-SP, com o objetivo de analisar os custos e a lucratividade na cultura de mamão Formosa "cultivar Tainung 01". O levantamento de dados necessários à realização da pesquisa nos aspectos ligados à elaboração das matrizes de coeficientes técnicos, base para estimativas de custos de produção, foi obtido diretamente junto a produtores da região, e a metodologia de custos foi baseada no custo operacional total e no custo total de produção. Os resultados econômicos satisfatórios mostram que a cultura do mamoeiro é viável na região.
\end{abstract}

Termos para Indexação: custos, lucratividade, mamoeiro, tecnologia.

\section{ANALYSIS OF PRODUCTION COST AND PROFITABILITY OF PAPAYA FORMOSA, IN SANTA FÉ DO SUL, SÃO PAULO STATE, BRAZIL}

\begin{abstract}
This work was carried out in Santa Fé do Sul (SP), intending to analyze costs and profitability in a cultivation of papaya Formosa 'cultivar Tainung 01'. The collection of necessary data to perform the research on the aspects related to the production and prices was obtained from local rural producers, and the cost methodology was based on the full operational cost and full production cost. The satisfactory economical results show that the papaya cultivation is feasible in this region.
\end{abstract}

Index Terms: costs, profitability, papaya.

\section{INTRODUÇÃO}

A origem da cultura do mamoeiro Carica papaya L. não é definida com precisão, sendo que a maioria dos pesquisadores considera que seu cultivo teve início na América do Sul, América Central ou no Sul do México, tendo daí se propagado por, praticamente, todas as regiões do mundo (Moura e Resende, 1986).

Segundo Nehmi et al. (2002), a produção mundial de mamão em 2001 foi de 5,4 milhões de toneladas, com uma área plantada de 341 ha. O Brasil destaca-se como o maior produtor, com 1,4 milhão de tonelada em uma área de 40 mil ha, mas exportou apenas 21 mil toneladas no ano de 2000, ocupando a terceira posição, atrás do México e da Malásia.

O Nordeste é a maior região produtora, destacando-se o Estado da Bahia que, em 2000, obteve uma produção de 823,4 mil toneladas em 25,5 mil ha, seguido pelo Estado do Espírito Santo, na região Sudeste, com uma área de 5,9 mil ha e uma produção de 424,6 mil toneladas.

No Estado de São Paulo, que já foi o maior produtor de mamão, a produção vem decaindo drasticamente a partir de 1980, em virtude da ocorrência do vírus do mosaico do mamoeiro, adquirindo a cultura o caráter migratório, tendo se deslocado principalmente para a Bahia, Espírito Santo e Pará (Martelleto et al., 1997).

O volume total de mamão comercializado no Entreposto Terminal de São Paulo, CEAGESP, em 2001, foi de 140.643 toneladas, das quais 52.379 toneladas pertencem ao mamoeiro do grupo "Formosa" e 88.264 toneladas ao grupo "Solo" - Havaí. Grande parte dessa produção vem de outros Estados, participando o Estado de São Paulo com apenas 3\% do total. O preço médio dos últimos cinco anos ${ }^{4}$, pago ao produtor em Linhares (ES), descontados os custos de comercialização e de pós-colheita, foi de $\mathrm{R} \$ 0,24 / \mathrm{kg}$ para o mamão Havaí e $\mathrm{R} \$ 0,19 / \mathrm{kg}$ para o mamão do grupo Formosa (Nehmi et al., 2002).

$\mathrm{Na}$ região Noroeste do Estado de São Paulo, mais especificamente o Escritório de Desenvolvimento Rural (EDR) de Jales, o mamoeiro que vem sendo plantado, é do grupo Formosa, mais comumente a cultivar "Tainung $\mathrm{n}^{\circ} 1$ ", que apresenta as seguintes características: peso médio de frutos de 900 gramas, polpa vermelhoalaranjada e de ótimo sabor, com produção média em torno de 60 toneladas/ha/ano (Luna, 1986).

Essa região vem destacando-se na produção de frutas, com uva, banana, citros, manga e coco, entre outras. Essas frutíferas surgiram como opções de diversificação, viabilizando a produção em pequenas propriedades rurais, em virtude de seu caráter produtivo e maior valor por área, aproveitando a mão-de-obra familiar e gerando novos empregos. Nesse sentido, a cultura do mamoeiro surge como mais uma opção viável na região. Iniciando a colheita dos nove aos doze meses do plantio no campo, permite produção contínua por, pelo menos, mais um ano. Esse período produtivo é limitado principalmente devido à ocorrência do vírus do mosaico do mamoeiro, tornando a condução da cultura, após esse período, economicamente inviável.

O presente trabalho tem como objetivo geral determinar os indicadores técnicos e econômicos para a cultura do mamoeiro do grupo Formosa "cultivar Tainung 01", no município de Santa Fé do Sul-SP, oferecendo assim subsídios aos produtores rurais, instituições financeiras e de fomento, quanto à tomada de decisão na continuidade ou iniciação na atividade.

\section{MATERIALEMÉTODOS}

\section{Fonte de dados e caracterização do local}

O levantamento de dados necessários à realização da pesquisa, nos aspectos ligados às matrizes de coeficientes técnicos e custos, foi obtido junto a três produtores rurais, indicados por técnicos da Casa da Agricultura do município de Santa Fé do Sul-SP, dentre aqueles que já trabalhavam com a cultura do mamão há algum tempo e apresentavam um mínimo de organização, para que as informações pudessem ser levantadas.

O município de Santa Fé do Sul, pertencente ao EDR - Jales-SP, encontra-se localizado na região Noroeste do Estado de São Paulo, apresentando as seguintes coordenadas geográficas: $20^{\circ} 12^{\prime}$ latitude Sul e 5055' longitude Oeste. Sua altitude média é de 365 metros, com uma precipitação média anual, nos últimos dez anos, de 1.100 a $1.200 \mathrm{~mm}$, podendo apresentar períodos de seca de até quatro meses, e uma temperatura média anual de $27,5^{\circ} \mathrm{C}$, sendo o clima tropical úmido. O solo é caracterizado como podzolizado Lins-Marília, variedade Marília, textura areno-argilosa.

Assim como Miqueletto et al. (2000), estes dados caracterizam

\footnotetext{
${ }^{1}$ (trabalho 092/2003). Recebido: 30/05/2003. Aceito para publicação: 19/01/2004.

${ }^{2}$ Mestranda da FE/UNESP, Campus de Ilha Solteira. Av. Brasil, 56, 15.385-000 Ilha Solteira.

${ }^{3}$ Docentes da FE/UNESP, Campus de Ilha Solteira. Av. Brasil, 56, 15.385-000 Ilha Solteira. E mail: maat@agr.feis.unep.br

${ }^{4}$ Média em R\$ deflacionado segundo IGP-DI (FGV) para agosto
} 
propriedades que utilizam técnicas de produção difundidas na região. Em função de aplicar-se em especificamente três propriedades, os resultados devem ser considerados com a devida atenção, pois, em qualquer atividade econômica, pode-se ter produtividades variando de acordo com o sistema de cultivo e com o gerenciamento adotado.

Os dados foram obtidos durante o ciclo de produção, mediante entrevistas e acompanhamento realizado diretamente junto aos produtores rurais, utilizando-se de planilhas, com a finalidade de levantar e apreender as questões mais ligadas à tecnologia de produção e identificar locais e formas de comercialização.

Para o cálculo do custo de produção, a estrutura foi baseada no custo operacional efetivo (COE) e custo operacional total (COT) (Matsunaga et al., 1976) e no custo total de produção (CTP). O COE, que é formado pelo conjunto das despesas efetivamente desembolsadas pelo produtor, compõe-se dos seguintes itens: despesas com operações mecanizadas, operações manuais, material consumido e outras despesas. Acrescentando-se ao COE depreciações e juros de custeio, tem-se o COT. Somando-se ao COT a remuneração ao capital fixo e a remuneração da terra, obtém-se o CTP. Para a remuneração da terra, foi considerado o valor de arrendamento da terra na região e $6 \%$ a.a. sobre a metade do COE como juros de custeio. Para o cálculo da depreciação dos bens fixos, foi utilizado o método linear.

Foram estimados os seguintes indicadores: a) receita bruta com a produção total obtida no período pelo preço médio recebido pelo produtor; b) lucro operacional obtido pela diferença entre a receita bruta e o custo operacional total; c) receita líquida obtida pela diferença entre a receita bruta e o custo total de produção; d) índice de lucratividade 1 obtido pela divisão entre o lucro operacional e receita bruta; e) índice de lucratividade 2 pela receita líquida dividida pela receita bruta, e f) preço de equilíbrio/(kg e caixa $21,0 \mathrm{~kg}$ ) obtido pela divisão do custo total e a produção.

Os preços médios foram coletados na região, em novembro de 2002, sendo apresentados em reais (R\$), e também convertidos para dólar (US\$), utilizando-se de uma taxa de câmbio do dólar comercial a R\$ 3,52 em novembro de $2002^{5}$.

\section{Caracterização do Sistema de Produção}

\section{Obtenção das mudas}

As mudas foram produzidas em parceria com o viveiro de mudas da Prefeitura Municipal de Santa Fé do Sul, através de um sistema no qual o produtor utiliza a estrutura do viveiro, constando de um ambiente protegido, com suportes em alumínio para as bandejas e cada uma com 130 tubetes, além do sistema de irrigação por microaspersão. Os tubetes são de polipropileno, com altura de $145 \mathrm{~mm}$, diâmetro interno/externo de 37 x $45 \mathrm{~mm}$ e volume com capacidade de $115 \mathrm{~cm}^{3}$.

Em contrapartida, o produtor adquire as sementes, o substrato e o adubo para mistura no substrato, e efetua os trabalhos de preparo do substrato e enchimento dos tubetes, bem como a semeadura com seus próprios funcionários. São semeadas em média quatro sementes por tubetes, e dos 30 aos 40 dias da emergência, com aproximadamente 20 $\mathrm{cm}$ de altura, vão para campo para serem plantadas com duas a três mudas por tubete, sendo a partir desse ponto comum o estiolamento das mudas.

Preparo de solo: foi o convencional, efetuando-se uma aração e duas gradagens, com aplicação e incorporação do calcário, além da construção dos terraços para conservação de solo.

Implantação: foi realizada uma sulcagem, marcando-se as linhas a cada 3,5 metros, e a cada 2,0 metros dentro da linha, o local das covas, misturando-se o adubo de plantio nesses locais, com uso de superfostato simples, na dosagem de $300 \mathrm{~g} /$ cova. Posteriormente, efetuou-se o plantio manual, utilizando-se de um tubete por cova, com duas a três mudas por tubete. Foram replantadas $2 \%$ das mudas.
Tratos culturais: foi utilizado roçadeira nas entrelinhas e capinas manuais nas linhas, até os seis meses de cultivo, e, posteriormente, aplicado herbicida. No primeiro ano, foi feita uma adubação de cobertura entre 60 e 90 dias do plantio em campo, na dose de $100 \mathrm{~g} /$ planta, com o formulado 20-00-20. No $2^{\circ}$ ano, aos treze meses do plantio, efetuou-se uma adubação com o Cloreto de Potássio, utilizando $80 \mathrm{~g} /$ planta, repetindo essa adubação aos 15-16 meses do plantio.

As pulverizações eram efetuadas preventivamente, após 60 dias do plantio em campo, visando principalmente ao controle do ácaro-branco (Polyphagotarsonemus latus), ácaro-rajado (Tetranychus urticae), e a doença pinta-preta ou varíola (Asperisporium caricae), utilizando-se de pulverizador costal de 20 litros, no primeiro ano. No segundo ano, com o maior porte das plantas, era utilizado equipamento tratorizado com tanque de 600 litros e mangueiras adaptadas para pulverização. Os defensivos agrícolas mais comumente utilizados são: fungicidas (mancozeb, chlorothalonil, oxicloreto de cobre), acaricidas (abamectin, dicofol mais tetradifon) e herbicidas (glifosate e diuron).

Foi efetuada uma desbrota aos seis meses do plantio, e a sexagem foi realizada de quatro a seis meses do plantio, conforme se apresentava o florescimento das plantas, deixando-se, sempre que possível, o mamoeiro hermafrodita do tipo elongata, cortando os demais rentes ao solo.

Colheita: iniciou-se aos 11 meses do plantio, em agosto/2001, com uma pequena produção, sendo a maior parte obtida durante os meses de novembro de 2001 a maio de 2002, perdurando até setembro/ 2002. A colheita foi efetuada manualmente, por meio de torção, sendo os frutos transportados internamente por carretas até um galpão. A produção é vendida a granel, e o intermediário é responsável pelas caixas.

\section{RESULTADOS E DISCUSSÕES}

O custo total de produção (CTP), estimado para a cultura de mamão Formosa, pode ser verificado na Tabela 01. No $1^{\circ}$ ano, o COE foi de $\mathrm{R} \$ 2.519,33$, as despesas com insumos atingiram quase $60 \%$ seguidas pela despesa com operações manuais. O CTP foi de R $\$ 3.104,78 / \mathrm{ha}$, e novamente as maiores despesas foram com os insumos, representando quase $50 \%$ deste valor, seguidas pelas despesas de mão-de-obra, com cerca de $32 \%$. No segundo ano, o CTP atinge R $\$ 5.444,03$ e as maiores despesas são com mão-de-obra ( $\mathrm{R} \$ 1.650,00)$, representando $30 \%$ do total. Neste item, só as despesas manuais com a colheita representaram mais de $98 \%$ do total gasto com mão-de-obra. A colheita do mamão é realizada manualmente e distribuída ao longo do ano todo, mostrando a viabilidade da cultura no aproveitamento da mão-de-obra rural e na geração de novos empregos. Das despesas com insumos (R $\$ 1.485,80)$, destaca-se o custo com defensivos, representando quase $90 \%$ dos gastos.

O custo total de produção, considerando os 2 anos, foi de R\$ $8.548,80 / \mathrm{ha}$ (US\$2.428,64), ou R $\$ 2,99 /$ caixa de $21 \mathrm{~kg}$ ou, ainda, $\mathrm{R} \$ 0,14 / \mathrm{kg}$, valor semelhante ao obtido em Pinheiros-ES, na produção de mamão Formosa irrigado, de R $\$ 0,135 / \mathrm{kg}^{4}$ (Nehmi et al., 2002).

A produção iniciou-se aos 11 meses do plantio em campo, colhidas por dois meses no primeiro ano e durante o segundo ano todo, tendo sido obtidos no total $59.976 \mathrm{~kg} / \mathrm{ha}$ de mamão, produtividade média obtida em outros trabalhos, como no de Luna (1986).

$\mathrm{Na}$ Tabela 02, são apresentadas estimativas de preços, lucratividade, receita bruta, receita líquida, preço de equilíbrio por kg e por caixa de $21,0 \mathrm{~kg}$. Foi considerado o preço médio recebido pelo produtor em novembro de 2002, de R $\$ 0,20 / \mathrm{kg}$, obtendo-se assim uma receita bruta de $\mathrm{R} \$ 11.995,20 / \mathrm{ha}$, e uma receita líquida de $\mathrm{R} \$ 3.446,40 / \mathrm{ha}$. Os índices de lucratividade são considerados bons, sendo de $35 \%$ em relação ao COT e de 28,7\% em relação ao CTP.

A cultivar tem potencial para maior produtividade e melhor preço, com a adoção de algumas técnicas de produção simples, que não vêm sendo utilizadas, como: correção e adubação do solo de acordo

\footnotetext{
${ }^{5}$ Corrigido para novembro de 2002 pelo IGP (DI) da FGV.
} 
TABELA 1 - Estimativa do custo total de produção de 59.976 kg/ha de mamão Formosa, em Santa Fé do Sul (SP), ciclo de 24 meses, em Reais de novembro de 2002.

\begin{tabular}{|c|c|c|c|c|c|c|c|}
\hline \multirow[b]{2}{*}{ ESPECIFICAÇÃO } & \multirow[b]{2}{*}{ Unid. } & \multirow{2}{*}{$\begin{array}{l}\text { V.U. } \\
\text { (R\$) }\end{array}$} & \multicolumn{2}{|c|}{$\mathbf{1}^{\circ}$ ANO } & \multicolumn{2}{|c|}{$2^{\circ} \mathrm{ANO}$} & \multirow{2}{*}{$\begin{array}{l}\text { V.T. } \\
\text { (US\$) }\end{array}$} \\
\hline & & & Qtde & $\begin{array}{l}\text { V.T. } \\
\text { (R\$) }\end{array}$ & Qtde & $\begin{array}{l}\text { V.T. } \\
\text { R\$) } \\
\end{array}$ & \\
\hline \multicolumn{8}{|l|}{$\begin{array}{l}\text { A. OPERAÇÕES MECANIZADAS } \\
\text { a1. Preparo de Solo }\end{array}$} \\
\hline Aração & $\mathrm{H} / \mathrm{M}$ & 19,35 & 2,2 & 42,57 & - & - & 12,09 \\
\hline Gradagem niveladora (2x) & $\mathrm{H} / \mathrm{M}$ & 19,23 & 1,8 & 34,61 & - & - & 9,83 \\
\hline Calagem & $\mathrm{H} / \mathrm{M}$ & 19,35 & 1,2 & 23,22 & - & - & 6,60 \\
\hline \multicolumn{7}{|l|}{ a2. Implantação } & 3,85 \\
\hline \multicolumn{7}{|l|}{ a3. Tratos culturais } & 9,83 \\
\hline Tratamento fitossanitário (18x) & $\mathrm{H} / \mathrm{M}$ & 19,80 & - & - & 27,0 & 534,60 & 151,88 \\
\hline Aplicação de herbicida (1x)(2x) & $\mathrm{H} / \mathrm{M}$ & 19,80 & 1,2 & 23,76 & 2,4 & 47,52 & 20,25 \\
\hline \multicolumn{6}{|l|}{ a4. Colheita } & - & 11,11 \\
\hline Transporte interno & $\mathrm{H} / \mathrm{M}$ & 19,35 & 4,0 & 77,40 & 36,0 & 696,60 & 219,89 \\
\hline Subtotal A & & & & 288,84 & & $1.278,72$ & 445,33 \\
\hline \multicolumn{8}{|l|}{ B. OPERAÇÕES MANUAIS } \\
\hline Prep. substrato e enchimento tubetes & H/D & 15,00 & 0,3 & 4,50 & - & - & 1,28 \\
\hline Semeadura nos tubetes & $\mathrm{H} / \mathrm{D}$ & 15,00 & 0,3 & 4,50 & - & - & 1,28 \\
\hline Marcação/cova e adubação química & $H / D$ & 15,00 & 3,5 & 52,50 & - & - & b2. Implantação \\
\hline Distribuição de mudas & $\mathrm{H} / \mathrm{D}$ & 15,00 & 0,3 & 4,50 & - & - & 1,28 \\
\hline Plantio & $\mathrm{H} / \mathrm{D}$ & 15,00 & 1,0 & 15,00 & - & - & 4,26 \\
\hline Replantio & $\mathrm{H} / \mathrm{D}$ & 15,00 & 0,1 & 1,50 & - & - & 0,43 \\
\hline \multicolumn{8}{|l|}{ b3. Tratos culturais } \\
\hline Capinas manuais $(3 \mathrm{x})$ & $\mathrm{H} / \mathrm{D}$ & 15,00 & 7,5 & 112,50 & - & - & 31,96 \\
\hline Pulverização costal (12x) & $\mathrm{H} / \mathrm{D}$ & 15,00 & 12,0 & 180,00 & - & - & 51,14 \\
\hline Adubação cobertura $(1 \mathrm{x})(2 \mathrm{x})$ & $\mathrm{H} / \mathrm{D}$ & 15,00 & 1,0 & 15,00 & 2,0 & 30,00 & 12,78 \\
\hline Desbrota & $\mathrm{H} / \mathrm{D}$ & 15,00 & 1,0 & 15,00 & - & - & 4,26 \\
\hline Sexagem & $\mathrm{H} / \mathrm{D}$ & 15,00 & 3,0 & 45,00 & - & - & 12,78 \\
\hline \multicolumn{8}{|l|}{ b4. Colheita } \\
\hline Manual (12x) (72x) & $\mathrm{H} / \mathrm{D}$ & 15,00 & 18,0 & 270,00 & 108,0 & $1.620,00$ & 536,93 \\
\hline Subtotal B & & & & 720,00 & & $1.650,00$ & 673,30 \\
\hline Total Operações & & & & $1.008,84$ & & $2.928,72$ & $1.118,63$ \\
\hline C. INSUMOS & & & & & & & \\
\hline Sementes & gramas & 10,50 & 48,50 & 509,25 & - & - & 144,67 \\
\hline Substrato & $\mathrm{sc}$ & 9,00 & 4,00 & 36,00 & - & - & 10,23 \\
\hline Adubo no substrato (04-14-08) & $\mathrm{kg}$ & 0,60 & 2,40 & 1,44 & - & - & 0,41 \\
\hline Fertilizantes e corretivos & & & & & & & \\
\hline Calcário dolomítico & ton. & 80,00 & 1,00 & 80,00 & - & - & 22,73 \\
\hline Adubo de plantio (Supersimples) & ton. & 520,00 & 0,43 & 223,60 & - & - & 63,52 \\
\hline Adubo de cobertura (20-00-20) & ton. & 620,00 & 0,15 & 93,00 & - & - & 26,42 \\
\hline Adubo Cobertura $(\mathrm{KCl})$ & ton. & 680,00 & & - & 0,23 & 156,40 & 44,43 \\
\hline Defensivos & & & & & & & \\
\hline Fungicida $01(2 x)(4 x)$ & $\mathrm{kg}$ & 17,50 & 1,20 & 21,00 & 4,80 & 84,00 & 29,83 \\
\hline Fungicida $02(2 x)(4 x)$ & $\mathrm{kg}$ & 40,00 & 1,20 & 48,00 & 4,80 & 192,00 & 68,18 \\
\hline Fungicida $03(2 x)$ & $\mathrm{kg}$ & 7,50 & & - & 4,80 & 36,00 & 10,23 \\
\hline Acaricida $01(12 x)(12 x)$ & lt & 170,00 & 1,80 & 306,00 & 3,60 & 612,00 & 260,80 \\
\hline Acaricida $02(6 x)(6 x)$ & lt & 42,00 & 3,60 & 151,20 & 7,20 & 302,40 & 128,86 \\
\hline Herbicida 01 (1x) (1x) & lt & 14,50 & 2,00 & 29,00 & 2,00 & 29,00 & 16,48 \\
\hline Herbicida $02(1 \mathrm{x})$ & $\mathrm{kg}$ & 22,00 & & - & 2,00 & 44,00 & 12,50 \\
\hline Espalhante adesivo & $1 \mathrm{t}$ & 6,00 & 2,00 & 12,00 & 5,00 & 30,00 & 11,93 \\
\hline Subtotal C (Insumos) & & & & $1.510,49$ & & $1.485,80$ & 851,22 \\
\hline Custo operacional efetivo (C.O.E) & & & & $2.519,33$ & & $4.414,52$ & $1.969,84$ \\
\hline Outras despesas & & & & 125,97 & & 220,73 & 98,49 \\
\hline Depreciação de máquinas e equip. & & & & 57,93 & & 277,69 & 95,35 \\
\hline Juros de custeio & & & & 75,58 & & 110,36 & 52,82 \\
\hline Custo operacional total (C.O.T) & & & & $2.778,81$ & & $5.023,30$ & $2.216,51$ \\
\hline Remuneração da terra & & & & 200,00 & & 200,00 & 113,64 \\
\hline Remuneração do capital & & & & 125,97 & & 220,73 & 98,49 \\
\hline Custo Total & & & & $3.104,78$ & & $5.444,03$ & $2.428,64$ \\
\hline Custo Total $\left(1^{\circ}\right.$ e $2^{\circ}$ ano $)$ & & & & & & $8.548,80$ & $2.428,64$ \\
\hline Custo/kg & & & & & & 0,14 & 0,04 \\
\hline Custo/caixa (21,0 kg) & & & & & & 2,99 & 0,85 \\
\hline
\end{tabular}


com análises de fertilidade; espaçamentos mais adensados; utilização de sistema de irrigação; desbaste de frutos; cuidados no manuseio póscolheita e melhoria nas embalagens para transporte e comercialização do produto, visando à melhoria na qualidade do fruto, proporcionando assim maior competitividade no mercado.

TABELA 2 - Estimativa de preços, lucratividade e ponto de equilíbrio de produção de $59.976 \mathrm{~kg}$ ไha de mamão Formosa, em Santa Fé do Sul (SP), ciclo de 24 meses em Reais de novembro de 2002.

\begin{tabular}{lrr}
\hline ESPECIFICAÇÃO & VALOR (R\$) VALOR (US\$) \\
\hline Preço médio recebido pelo produtor/kg & 0,20 & 0,06 \\
Receita Bruta & $11.995,20$ & $3.407,73$ \\
Custo Operacional Efetivo & $6.933,85$ & $1.969,84$ \\
Custo Operacional Total $\left(1^{\circ}\right.$ e $2^{\circ}$ anos) & $7.802,11$ & $2.216,51$ \\
Custo Total de Produção $\left(1^{\circ}\right.$ e $2^{\circ}$ anos) & $8.548,80$ & $2.428,64$ \\
Lucro Operacional & $4.193,09$ & $1.191,22$ \\
Receita Líquida & $3.446,40$ & 979,09 \\
Índice de Lucratividade (lucro operacional) & $34,96 \%$ & - \\
Índice de Lucratividade (receita líquida) & $28,73 \%$ & - \\
Preço de Equilíbrio/kg & 0,14 & 0,04 \\
Preço de Equilíbrio/caixa 21,0 kg & 2,94 & 0,85 \\
\hline
\end{tabular}

Fonte: Dados da pesquisa.

\section{CONCLUSÕES}

Pode-se considerar a cultura do mamoeiro como mais uma alternativa viável de cultivo para a região de Jales (SP), tendo apresentado resultados econômicos satisfatórios, além de precocidade na produção. Também se observa que a maior produção ocorre em função do período chuvoso, visto os produtores não adotarem um sistema de irrigação, ficando dependentes do regime pluviométrico da região.

O período de colheita, comumente definido por apenas um ano, deve-se principalmente à ocorrência de viroses, tornando a cultura inviável economicamente após esse período.

Ressalta-se que, como os dados se referem a três produtores de mamão que utilizam técnicas de produção difundidas na região, os resultados devem ser vistos com atenção, pois a produtividade pode variar, dependendo do sistema de cultivo.

Considera-se também que a cultura se apresenta eficiente na geração de empregos, aproveitando a mão-de-obra rural, principalmente a familiar das pequenas propriedades.

\section{REFERÊNCIASBIBLIOGRÁFICAS}

LUNA, J. V. U. Variedades de mamoeiro. Informe Agropecuário, Belo Horizonte, v.12, n.134, p.14-17, 1986.

MATSUNAGA, M. Metodologia de custo de produção utilizada pelo IEA. Agricultura em São Paulo, São Paulo, v.23, n.1, p.123-39, 1976.

MARTELLETO, L. A. P.; MALDONADO, J. F. M.; VIEIRA, A. et al. A cultura do mamão: perspectivas, tecnologias e viabilidades. Niterói: PESAGRO-RIO, 1997. 28p. (Documentos, 37).

MIQUELETTO, D.F.; CARDOSO, J.L.; MARTIN, N.B. Avaliação econômica da produção comercial de uva niagara: uma aplicação do software CUSTAGRI 1.0. Informações Econômicas, São Paulo, v.30, n.11,p. 7-15, 2000.

MOURA, P. A. M. de; RESENDE, L. M. A. Aspectos econômicos da cultura do mamoeiro. Informe Agropecuário, Belo Horizonte, v.12, n.134, p.3-7, 1986.

NEHMI, I. M. D; FERRAZ, J. V.; NEHMI FILHO, V. A.; SILVA, M. L. M. da. (Coord.) AGRIANUAL 2003: anuário da agricultura brasileira. São Paulo: FNP Consultoria \& Comércio, 2002. p. 378-386. 